\title{
A Survey of Routing Issues and Associated Protocols in Underwater Wireless Sensor Networks
}

\author{
Muhammad Khalid, ${ }^{1}$ Zahid Ullah,, Naveed Ahmad, ${ }^{2}$ Muhammad Arshad, ${ }^{1}$ Bilal Jan, \\ Yue Cao, ${ }^{4}$ and Awais Adnan ${ }^{1}$ \\ ${ }^{1}$ Institute of Management Sciences (IMS), Peshawar, Pakistan \\ ${ }^{2}$ University of Peshawar, Peshawar, Pakistan \\ ${ }^{3}$ Sarhad University of Science \& Information Technology, Peshawar, Pakistan \\ ${ }^{4}$ Northumbria University, Newcastle upon Tyne, UK \\ Correspondence should be addressed to Yue Cao; yue.cao@northumbria.ac.uk
}

Received 18 September 2016; Revised 5 March 2017; Accepted 19 March 2017; Published 22 May 2017

Academic Editor: Banshi D. Gupta

Copyright (C) 2017 Muhammad Khalid et al. This is an open access article distributed under the Creative Commons Attribution License, which permits unrestricted use, distribution, and reproduction in any medium, provided the original work is properly cited.

Underwater wireless sensor networks are a newly emerging wireless technology in which small size sensors with limited energy and limited memory and bandwidth are deployed in deep sea water and various monitoring operations like tactical surveillance, environmental monitoring, and data collection are performed through these tiny sensors. Underwater wireless sensor networks are used for the exploration of underwater resources, oceanographic data collection, flood or disaster prevention, tactical surveillance systems, and unmanned underwater vehicles. Sensor nodes consist of a small memory, a central processing unit, and an antenna. Underwater networks are much different from terrestrial sensor networks as radio waves cannot be used in underwater wireless sensor networks. Acoustic channels are used for communication in deep sea water. Acoustic signals have many limitations, such as limited bandwidth, higher end-to-end delay, network path loss, higher propagation delay, and dynamic topology. Usually, these limitations result in higher energy consumption with a smaller number of packets delivered. The main aim nowadays is to operate sensor nodes having a smaller battery for a longer time in the network. This survey has discussed the state-of-the-art localization based and localization-free routing protocols. Routing associated issues in the area of underwater wireless sensor networks have also been discussed.

\section{Introduction}

Underwater wireless sensor network (UWSN) is a newly emerging wireless sensor technology which is used to provide the most promising mechanism and methods that are used for discovering aqueous environment. It is used in various key applications in underwater environment. It works very efficiently in many situations like commercial, military, emergency monitoring, data collection, and environmental monitoring purposes. In this kind of networks, small sensors node are deployed in sea water. These nodes are equipped with central processing unit, antenna, and battery. Batteries in these sensor nodes are nonrechargeable and nonreplaceable. These sensors collect the required data and send it to sinks which are installed offshore [1]. Autonomous underwater and unmanned vehicles which are equipped with sensors that are specially designed for underwater communication [2], which are mostly used in areas where humans are unable to explore underwater resources directly. Information about natural resources lying underwater is obtained by unmanned vehicles and forwarded to sinks $[3,4]$. Radio waves cannot be used in underwater communication; therefore, acoustic communication is needed [5]. Communication through acoustic links is very costly as compared to radio link. Acoustic links have high end-to-end delay and low bandwidth. Once data packet is received at sink then it is forwarded through radio waves to other sinks and base stations [6]. Underwater networks have very limited resources in comparison to terrestrial wireless sensor networks. Protocols suites that are used in other networks cannot be directly applied to underwater 
networks [7]. Till date many protocols have been proposed for underwater sensor networks. These are mainly divided into two types which are localization based and localization-free protocols [8], where the term localization means knowledge of nodes and sink in network. Those routing protocols which need prior geographic information of other nodes and sinks are localization based routing protocols, while those routing protocols which do not need any earlier geographic information for routing can be categorized as localizationfree routing protocols $[7,9]$.

The rest of the paper is organized as follows. Section 2 discussed the architecture of terrestrial wireless sensor network. In Section 3, the architecture of underwater wireless sensor network is explained. Section 4 has defined the related work, while localization based and localization-free routing protocol are discussed in Sections 5 and 6, respectively, and finally conclusion is drawn in Section 7.

\section{Terrestrial Wireless Sensor Network}

Wireless sensor network is newly emerged technology, whose purpose is to perform monitoring tasks in different fields of operation as well as take necessary actions according to received data and instructions [10]. WSN is used in military purposes, security monitoring, flood monitoring, health monitoring, border monitoring, and many more [11]. WSN consist of small sensor nodes and sinks. Sensors are batteryoperated having small memory, transceiver, and receiver that are used to send and receive data [12]. Sinks are usually supplied with external power and are used to collect data from sensor. A sink in WSN is considered as data center which collects data from all sensors and forwards it to other base stations. Nodes in WSN are deployed from plane which adopts a random topology. To make efficient communication between nodes, energy-efficient routing protocols are needed. A few routing protocols that are used in WSN are discussed below.

In various applications of WSN, deployment of sensor nodes is performed in ad hoc fashion and no precautions for deployment stage are used. Once deployed, they must be able to develop a structure as per need of the network, as sensor nodes are battery-operated and these nodes are expected to continue their operation for a relatively long period of time [13]. In many of the cases it is usually very difficult and almost even impossible to change batteries or recharge them. WSN has many limitations in itself like high level of unreliability of the sensors, limited battery power, low memory, network control and management functions, network security, localization, and synchronization. Several shortcomings have been observed using traditional routing protocols and are because of energy constraint nature of such networks [14]. Like in flooding technique, a node sends data received by it to all nodes in the network and this process repeats itself at every node until data reached to sink [14]. It is observed that this technique does not take into account the level of energy consumption. So we encounter the problem of receiving multiple copies at the end node and much energy is consumed during this process [15]. As already mentioned, flooding is blind technique and packets get duplicate and also circulate in the network, this will lead to implosion problem [14]. When two sensors are in the same region so they will sense the same data and ultimately they will forward the same data and as a result duplicate copy of the same packet will be generated [16]. To overcome the problem of flooding and duplication of the same packet another technique called gossiping can be applied. In this kind of process when a sensor senses data, it simply forwards packet to one of their neighbors by selecting them randomly and without any kind of mechanism. This process continues until packet reaches the sink. The main problems that are faced during gossiping are end-to-end delay and path loss. As only one packet is forwarded if the packet is dropped at any sensor then data will be lost. Also there is not specialized mechanism whether data is moving in right direction or not. Below are few famous routing protocols used in wireless sensor networks.

2.1. Low-Energy Adaptive Clustering Hierarchy. Low-energy adaptive clustering hierarchy (LEACH) is considered to be most popular hierarchical routing protocol [12]. LEACH form multiple clusters based on received signal strength and a cluster head is chosen through election or direct selection. This selected cluster head will pass on data to sink. Data is then forwarded to other cluster heads and finally delivered to sink. LEACH is known as the first and the most popular energy-efficient hierarchical clustering algorithm designed for WSN which was suggested for reduced power consumption during routing in WSN. Using LEACH the task of clustering is rotated among nodes which is based on duration during communication. In LEACH protocol a cluster head can directly communicate with the base station and can send data directly to base station. For the purpose of long network life time and long term monitoring, all the cluster heads work together and work in a group. To work for long time and make the network alive and operational for a longer period of time, first of all a cluster head is elected according to the rules defined by the protocol. After election, one node is selected as cluster head. After selection of cluster head when a node in a cluster senses some data, it simply forwards it to cluster head and then that cluster forwards it to another cluster head and ultimately it reaches its destination or sink. There are multiple kinds of operations and mechanisms taken into consideration while performing network operation, like RTS/CTS, which is performed before forwarding data to any node in the network [12].

\subsection{Power-Efficient GAthering in Sensor Information Systems.} Power-Efficient GAthering in Sensor Information Systems (PEGASIS) is routing protocol for WSN [17]. Unlike LEACH it does not form any cluster. PEGASIS developed a chain like route from end node towards sink that is used to send data to sink. PEGASIS uses hop-by-hop mechanism to forward data to sink. PEGASIS was an earlier extension of LEACH which actually forms a chain instead of forming clusters which were formed in LEACH. The mechanism of its working is quite simple in which it develops a chain. In this chain a single node is selected from nodes through which data is forwarded and the same process is repeated until it reaches sink. Hence 


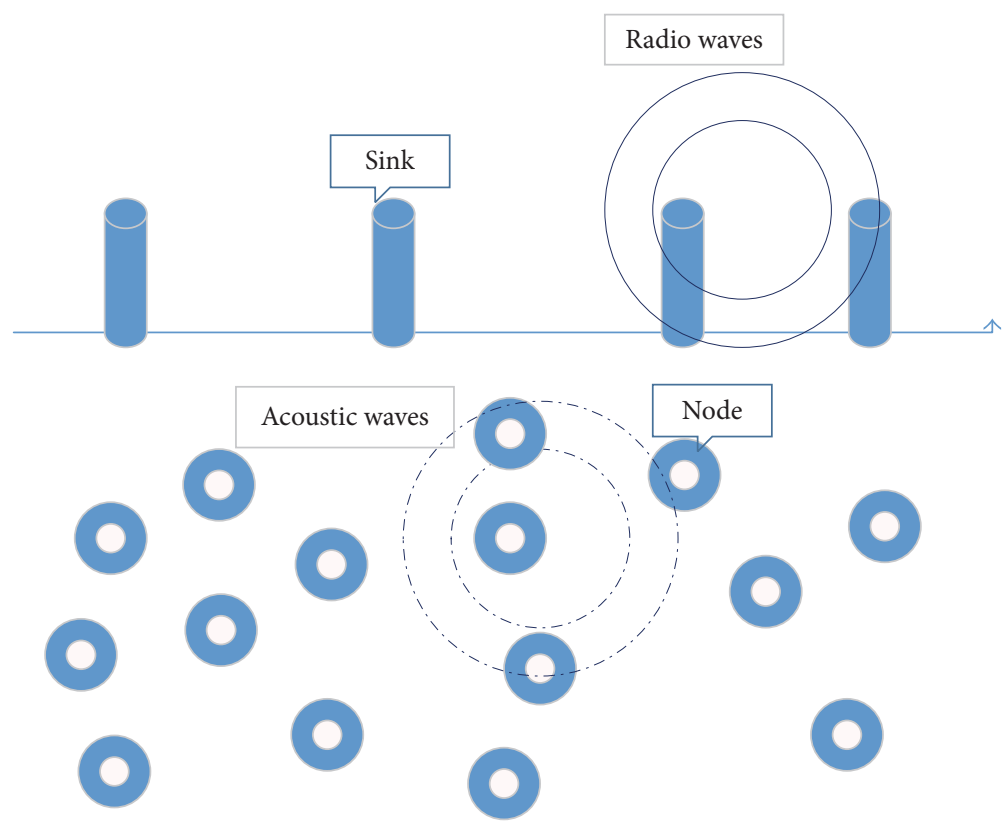

FIgURE 1: Network architecture.

data is gathered at every node and forwarded to next node. While performing chain construction, greedy algorithm is adopted. In PEGASIS it is also assumed that every node has all the information about the network. Using greedy approach it does not take into account any energy efficiency mechanism. Hence some nodes are used very frequently and die very early, every time this protocol forms a different topology.

\subsection{Threshold Sensitive Energy-Efficient Sensor Network.} Threshold Sensitive Energy-Efficient Sensor Network (TEEN) [18] is a routing protocol which is used for responsive networks where a fast response is required. It is used in such application where data is critical and each and every packet happens to be very useful. It also forms clusters where a cluster head sets a hard and soft threshold for packet forwarding. It consumes less amount of energy as compared to other protocols. TEEN sets a threshold for data forwarding. This threshold is sensed by other nodes. The drawback in this scheme is that if thresholds are not reached then they will not communicate with each other.

\section{Underwater Wireless Sensor Networks}

UWSN is a wireless technology which has gained worldwide attention these days. It provides the most promising mechanism used for discovering aqueous environment very efficiently for many scenarios like military [19], emergency, and commercial purposes. Autonomous underwater and unmanned vehicles are equipped with sensors that are specially designed for underwater communication, which are mostly used in those areas where exploration for natural resources which lie underwater is needed [20]. These unmanned vehicles gather data of resources lying underwater and send is back to offshore sinks which is forwarded to other stations for further processing. Radio waves cannot be used in underwater communication; therefore acoustic communication is used. Once data packet reaches sink then it is forwarded through radio waves to other sinks and stations [3].

Underwater wireless sensor environment is much different from that of terrestrial. Acoustic waves are used in underwater communication while terrestrial network uses radio waves [4]. Normally the problems that occur during communication in underwater communication are due to dense salty water and electromagnetic as well as optical signal does not work in UWSN [6]. Due to high attenuation and absorption effect, signals cannot travel long distances [21]. Hence to overcome these problems, acoustic communication is used. It can overcome these problems and provide a better transfer rate in underwater environment [6]. Due to limitations of acoustic communication, the communication speed slows down to $1500 \mathrm{~m} / \mathrm{sec}$, that is, speed of sound from speed of light. Due to lower speed there is usually long propagation delay and higher end-to-end time [22]. In acoustic communication bandwidth is very limited which is less than $100 \mathrm{KHz}$ [1]. In underwater scenarios sensor nodes are usually considered static but it is also considered that they may move from 1 to 3 meters/second because of flow of water [1]. Sensor nodes used in underwater network are batteryoperated and it is almost impossible to replace their batteries. In underwater applications a multihop or multipath network is required and data is forwarded by passing all nodes towards sink. Once data is received at any of the sinks then data is forwarded to concerned node through radio transmission [23]. Figure 1 represents network architecture of UWSN.

While using those routing protocols which require higher bandwidth [24] and usually have higher delay at the node's end, as it is known that acoustic communication does not support higher bandwidth, using routing protocols that are 

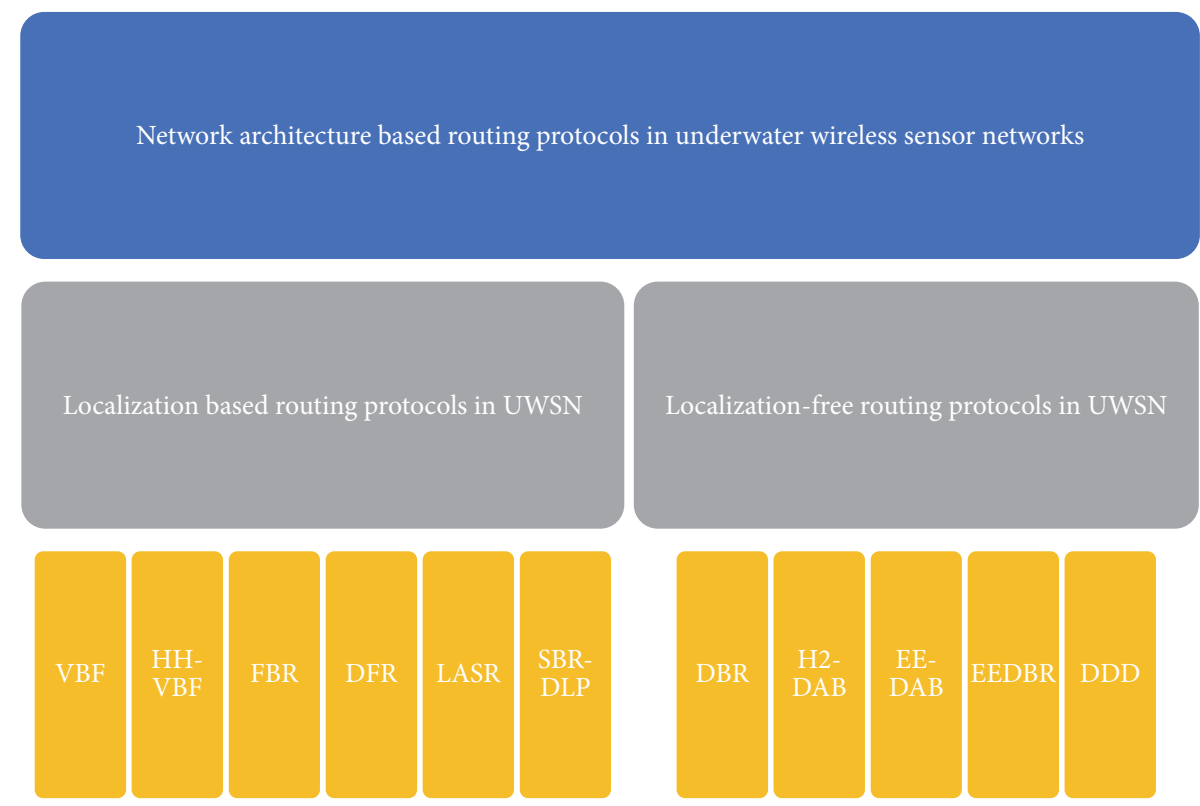

FIGURE 2: Routing protocols in UWSN.

used in terrestrial network will not perform good due to their higher delay and high energy consumption [25]. Using underwater network, topology does not remain the same as node moves due to flow of water [26]. In localization based protocol, geographical network information is necessary so it possesses more control messages than localization-free protocol, in which no prior network information is necessary [27]. Figure 2 shows the start of the art localization based and localization-free routing protocols in UWSN.

Oceans are vast and cover around one hundred and forty million square miles, which is more than 70 percent of Earth total surface. Not only has it been considered major source of the nourishment, but also with span of time it is taking a good role in transportation stuffs, defense as well as adventurous purposes, and natural resources presence [28]. As underwater resources play a vital role in human life, very less of this area is explored [29]. Less than ten percent of the whole ocean volume is investigated, while a large amount of area is still not explored. The increase in roles of the oceans in the lives of humans [30] and these largely unexplored areas have a lot of importance [31]. On one hand the traditional approaches for underwater monitoring have got several disadvantages while on the other side human presence is not considered to be feasible for underwater environment [32].

3.1. Node Architecture. A general architecture of underwater wireless sensor node is composed of five main elements, which are energy management unit, data sensing unit, depth measuring unit, communication unit, and central processing unit [33]. As shown in Figure 3.

Processing unit is responsible for all kinds of data processing where energy management unit has the responsibility to manage the remaining energy of the node and consumption of energy in run time [34]. Data sensing unit is used to sense

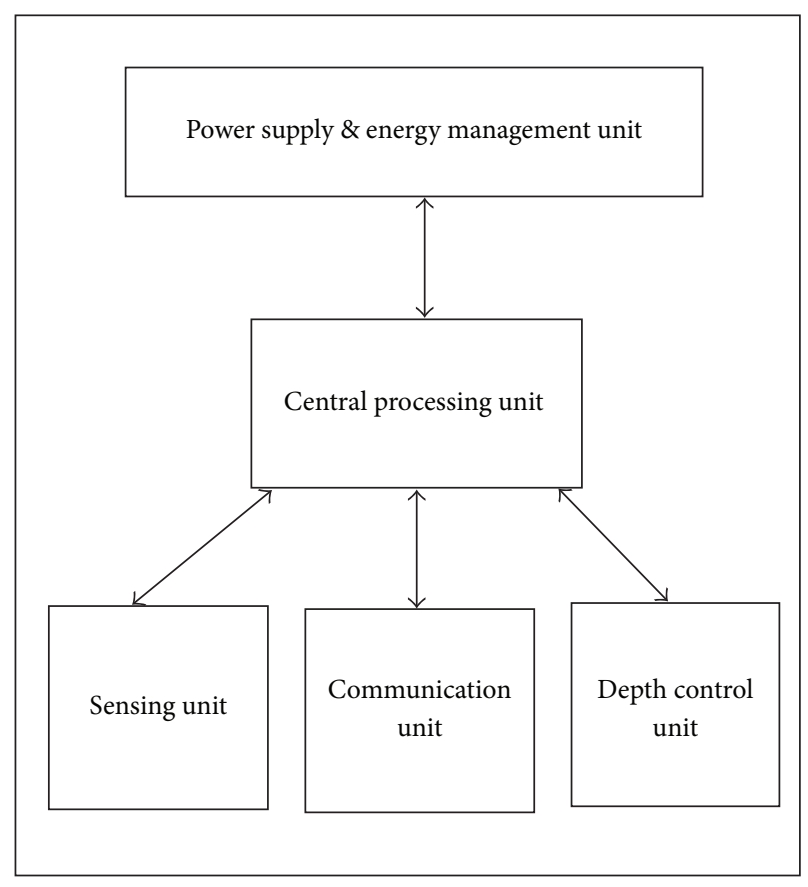

FIgURE 3: Architecture of a typical underwater sensor node.

data. It always remains active even when node is in sleep mode [35]. Communication unit is responsible for all kinds of data communication whereas depth measuring unit is used for measuring depth of node when it is deployed in sea [14].

3.2. Constraints in Underwater Wireless Sensor Network. UWSN carries multiple differences in comparison with terrestrial area network, where nodes are stable or move in a 
specified direction while in underwater networks they usually displace their positions with the flow of water. Acoustic communication is used for underwater transmission which minimizes the bandwidth for data transferring. A few constraints are discussed below.

(i) Limited Bandwidth. Acoustic channels offer very limited amount of bandwidth, as radio transmission cannot be used for underwater communication [3]. Acoustic communication requires more energy to send a small amount of data, due to its lower bandwidth.

(ii) Propagation Delay. Due to use of acoustic communication, propagation speed becomes five times slower than that of radio frequency, that is, $1500 \mathrm{~m} / \mathrm{sec}$ [4], which obviously results in high propagation delays in the network.

(iii) Limited Energy. Nodes that are used in underwater communication are larger in size [3]; hence they require larger amount of energy for communication. Furthermore, acoustic channels also required more energy for communication than terrestrial network. Batteries in UWSN cannot be recharged or replaced; therefore, use of energy-efficient communication is always a need to provide network with higher life time.

(iv) Limited Memory. In UWSN nodes are small in size and therefore they have a limited amount of storage and processing capacity [6].

(v) Variable Topology. UWSN does not have a specific or static topology as flow of water makes it difficult for node to remain static in one place; therefore, node moves randomly.

\section{Related Work}

Akyildiz et al. in [3] discussed architecture of acoustic communication. 2D and 3D underwater communication have also been discussed. They also discussed different layers of communication in underwater networks. Multiple open researches have been provided in this survey paper. However, discussion about routing protocol in underwater networks and their comparison have not been discussed. In [22], Cui et al. discussed the differences between terrestrial and underwater network. Like in UWSN, low bandwidth, propagation delay, high bit error rate, floating of node, and limited energy have been discussed. Multiple unique characteristics of UWSN their benefits and flaws were discussed. Similarly no proper discussion about routing protocols has been carried out, while in [15], Ayaz et al. explained the basis architecture of underwater networks. Multiple schemes of routing in underwater communication have been discussed in this survey. They also discussed multiple routing protocols. Detailed diagrams were presented to get a good understanding of different routing protocols but still no comparison was carried out. Chandrasekhar et al. in [23] have discussed the term localization. Localization is a phenomenon in which the location of node is already known to other nodes and sinks, which make it easier for sink to locate and communicate it. Multiple schemes like area based scheme, area localization scheme, and hop count based scheme have been discussed [36]. In Energy-Efficient Dynamic Address Based (EE-DAB) routing [37] every node is assigned Node-ID, S-HopID, and C-HopID. Node-ID shows the physical address of node; SHopID consists of two digits which show how many hops away one or two sinks are. Left hop is considered as the highest priority and is selected as primary route. The CHopID also consists of 2 digits which show how many hops the receiving nodes are away from courier nodes. Acoustic communication uses more energy than that of radio communication. As wireless sensor nodes are batteryoperated and higher energy consumption leads to a serious problem, thus energy efficiency has become a major problem in underwater wireless sensor networks. In [38], a delaytolerant protocol is proposed which is called delay-tolerant data dolphin scheme. This proposed scheme is designed for delay-tolerant systems and applications. In these protocols all the sensing nodes stay static and data sensed by static nodes are passed on to data dolphin which acts as courier nodes. So in this methodology high energy consumed hopby-hop communication is avoided. Data dolphins which act as courier nodes are provided with continuous energy. In the architecture all the static nodes are deployed in the sea bed. These static sensors go into sleep mode if there is no data to sense and they periodically wake up when they sense some data. After sensing some kind of desired data they simply forward this data to courier nodes which are also called data dolphins. These data dolphins take this data and deliver it to base station or sink. The number of dolphin nodes depends upon the kind of network and its application and the number of nodes deployed in the network. In [39], a virtual sink architecture is proposed where sinks are connected with each other through radio communication. In this scheme, each and every sink broadcasts a hello packet which is also known as hop count update packet. After receiving hello packet by nodes, a hop count value is assigned to every sensor. These hop counts are used for selection of forwarding nodes while sending data packet from one node to another. However, the proposed scheme has a few limitations which include redundant transmission, that is, transmission of a same packet multiple times. A detailed comparison of routing protocol is provided in Table 1 .

\section{Localization Based Routing Protocols}

Routing protocols which need prior network information before sending any data over the network are called localization based routing protocols. These protocols usually need geographical information of all nodes in the network as well as information about sink location. These protocols are considered to be less energy-efficient; most of the energy is wasted in collecting their geographical information. These records are updated dynamically after fixed interval of time as node's position may change due to water flow. Routing protocols basically need the assumption of sensor nodes in underwater sensor networks [36]. In localization based 


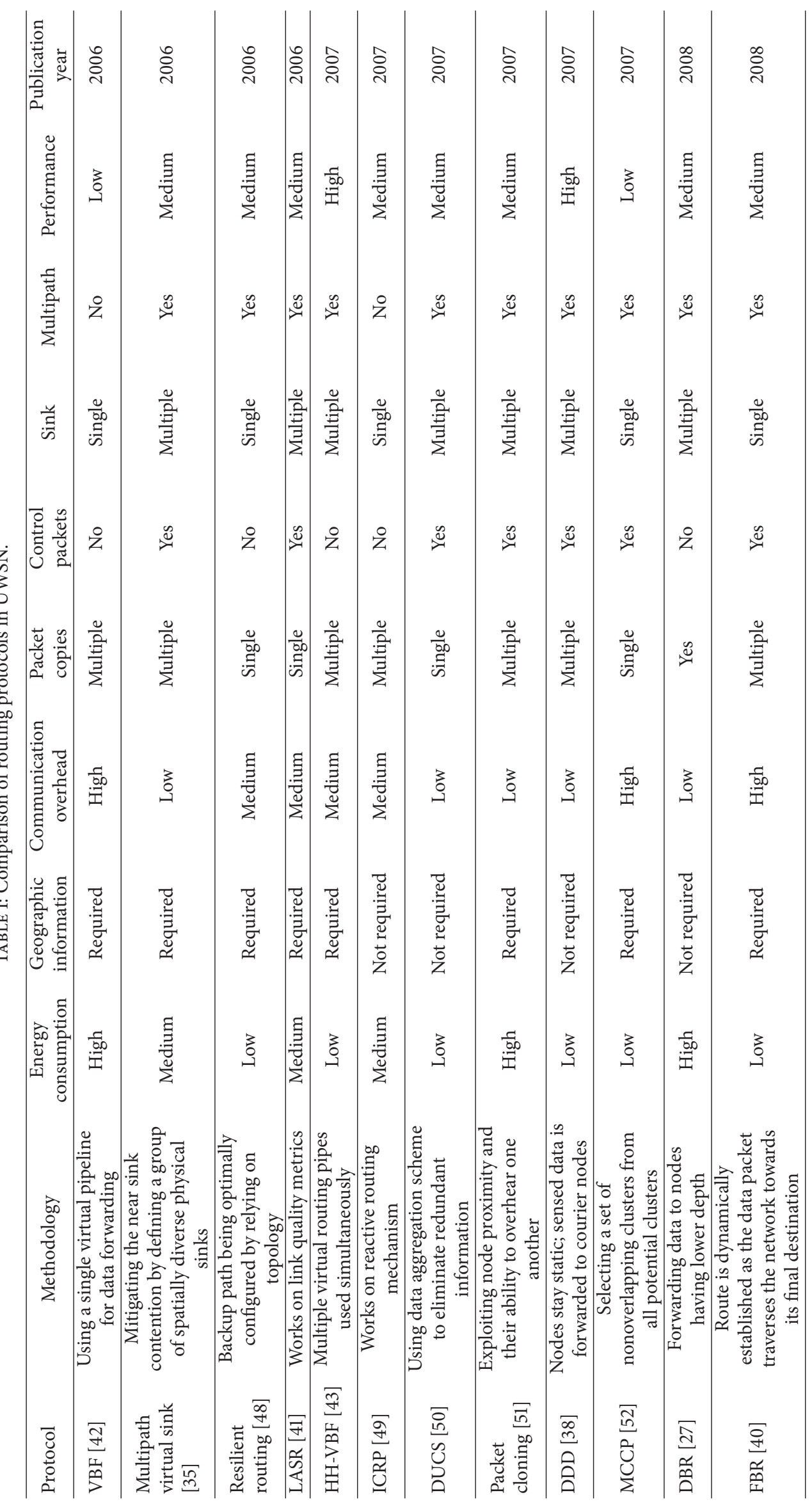




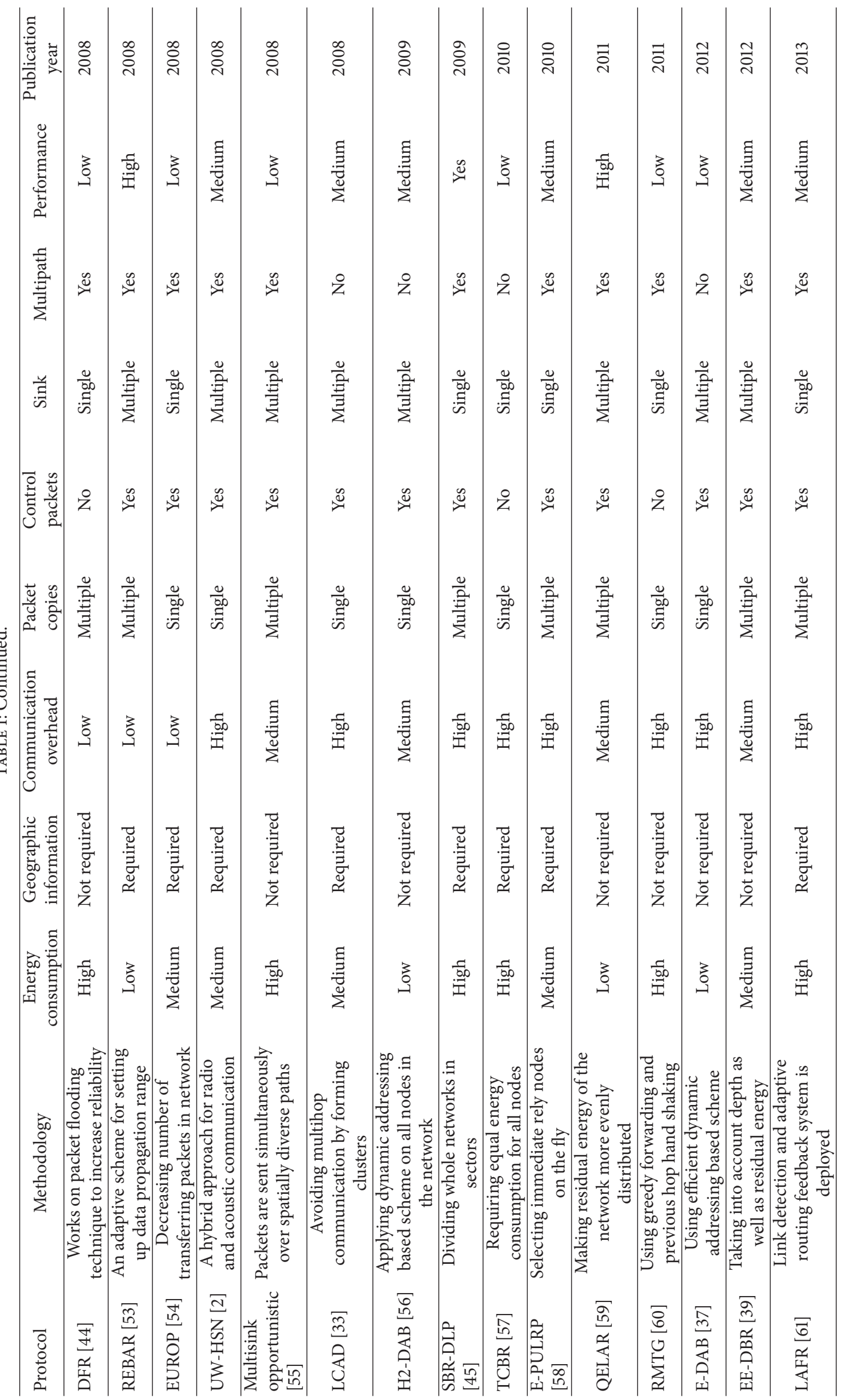




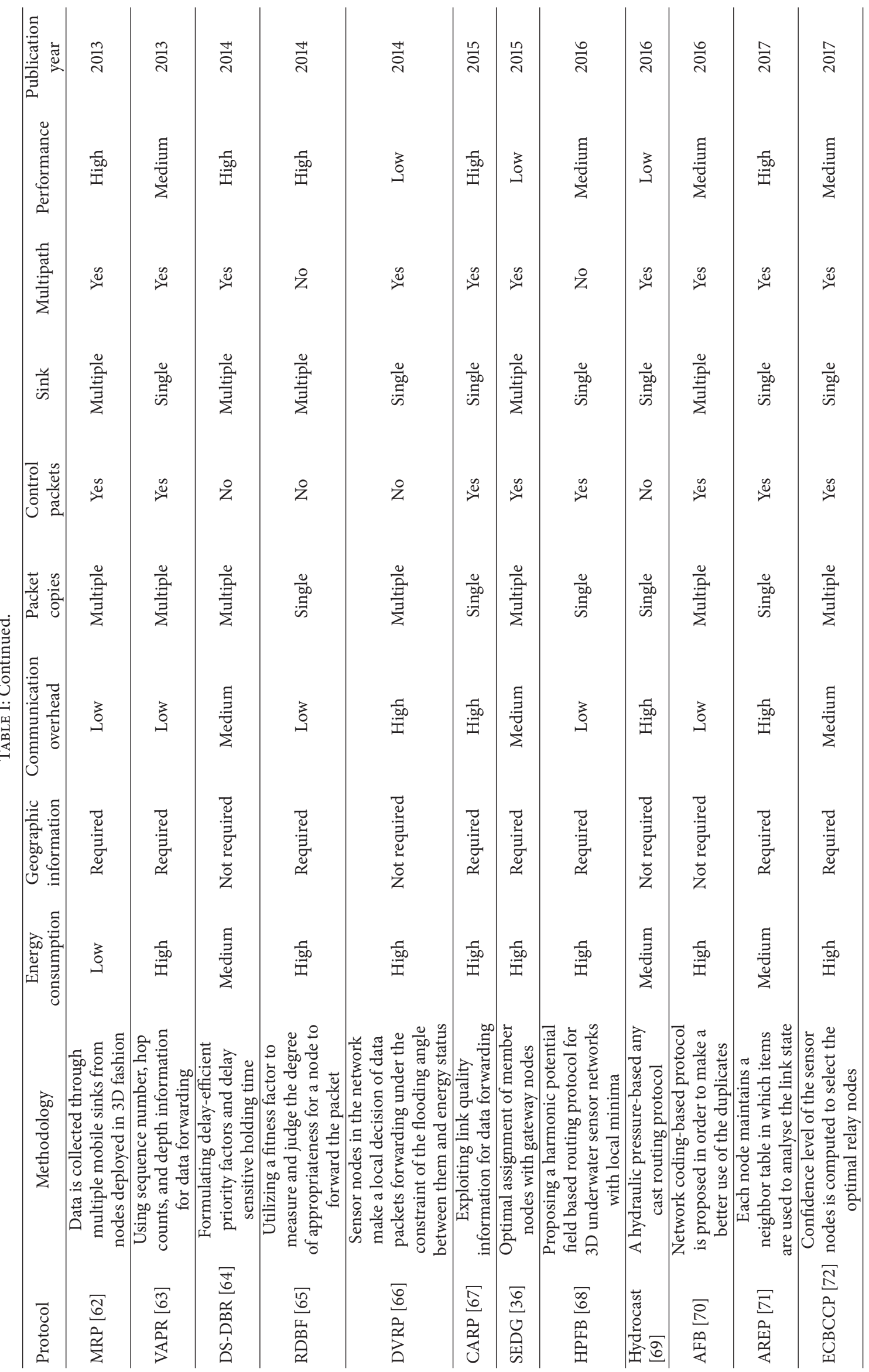


routing protocols a node needs the information of all the network nodes as well as of sink such that in this scenario prior network information is needed for a node $[1,2,33]$. In [38], Focused Beam Routing protocol requires geographical information of itself and of destination. It uses RTS/CTS mechanism to forward data. Sender protocol transmits the RTS and receiver of the packet sends back CTS. In vector based forwarding [40], a source node develops a vector based routing pipe starting from sender node towards sink. Various times it is hard to find an available node in the routing pipe for data forwarding. SBR-DLP [41], also known as sector based routing, with destination location prediction is a localization based routing algorithm where node is not needed to have information of its neighbor nodes. It only needs to carry its own information and preplanned movement of sink although it decreases the flexibility of the network and it will only move around in a scheduled manner. Table 2 provides a detailed overview of localization based routing protocols in UWSN.

5.1. Vector Based Forwarding. Vector based forwarding (VBF) [42] is a routing scheme which requires maintenance and frequent recovery of routing paths. This is a position based routing protocol in which a very less amount of nodes is actually involved in routing process. Therefore, a very small number of nodes play their role in the operation of data forwarding, as the very important phenomenon in routing is data forwarding where a very small number of sensor nodes take part in this data forwarding operation. In this scheme a sensor already knows its location and location of the destination. It is also considered that a node already knows all the nodes that are involved in the routing process or forwarding of a node, which include the source node, forwarding intermediate nodes, and the final node or the destination. The idea of this protocol is based on virtual routing pipe and all forwarding data is sent through this pipe. As routing pipe phenomenon is involved in this scheme most of the time nodes that are used during routing process are the nodes that lies in the area of the pipe.

5.2. Hop-by-Hop-Vector Based Forwarding. Hop-by-hopvector based forwarding HH-VBF [43] is an advanced version of VBF. In this scheme main focus is on robustness and problems faced by its earlier version [42]. The same concept as was used in VBF is also used here. Concept of virtual pipe is deployed here. But here instead of single virtual routing pipe which is used by VBF, single routing pipe is used for every forwarder which means a single pipe for every forwarding hop, as we observed that only a few nodes are involved in VBF while in $\mathrm{HH}-\mathrm{VBF}$ multiple routing pipes are created, which ultimately result in lower end-to-end delay and higher energy efficiency. Using this mechanism every node can make a decision about the direction of pipe which is based on node's current location.

5.3. Directional Flooding-Based Routing. Directional Flooding-Based Routing (DFR) [44] is localization based routing protocol. In DFR, flooding phenomenon is used where packet is sent through flooding mechanism to final destination. In this protocol it is assumed that every node

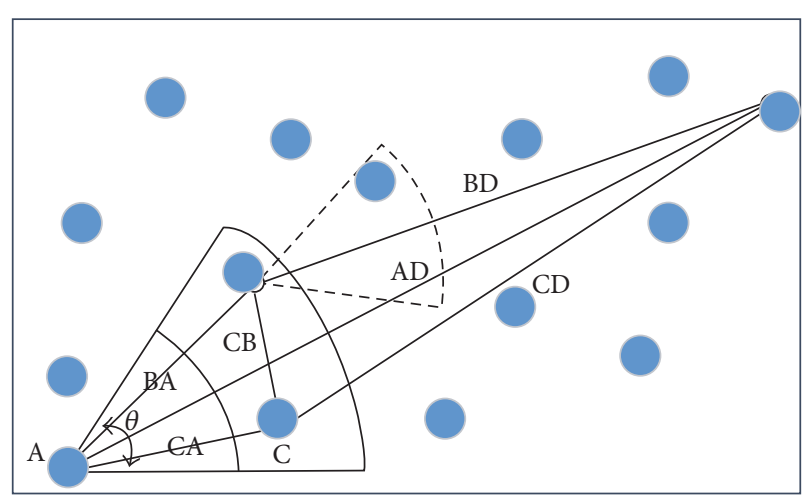

FIGURE 4: Working of FBR protocol.

must know the location of itself and one-hop-away node and final destination. Only a limited number of nodes take part in routing process. In this scheme the flooding zone is decided by FS and FD, where S is source node and D is destination node while $\mathrm{F}$ is receiving node, usually sink.

5.4. Location-Aware Source Routing. Location-Aware Source Routing (LASR) [41] is an advanced version of DSR. Link quality metrics and location awareness technique are used by LASR routing scheme. Earlier protocol only depended upon the shortest path metrics and in the end it led to bad performance.

5.5. Focused Beam Routing. Focused Beam Routing (FBR) [40] is localization-free routing protocol, in which sender node knows only its own location information and location information of final destination. No further geographical information of other nodes is necessary which results in less control messages and high throughput. The mechanism that FBR has adopted for data forwarding is that next hop is selected keeping in view final destination.

First of all an RTS packet is multicast in its neighbors, which contains location of sender and final destination. This multicast operation is performed at low power level. If sender does not receive any response then level is increased.

Figure 4 explained data forwarding method which is used in FBR, where node A has a data packet that is required to be sent to the destination node which is $\mathrm{D}$. To complete this operation, node $\mathrm{A}$ has to multicast a request in order to send (RTS) packet to its neighboring nodes which lie in its range, as this RTS packet contains the location of node A and that of final destination D. Initially, this multicast action will be performed at the lowest power level, which can be increased if neither of the nodes is found as next hop in the transmission range. For this purpose they define finite power levels, which are P1 through PN. In FBR if no node lies in senders range then it has to rebroadcast RTS which results in consumption of high energy.

5.6. Directional Flooding-Based Routing (DFR). DFR [44] is location based routing protocol. In DFR, flooding phenomenon is used where packet is sent through flooding 


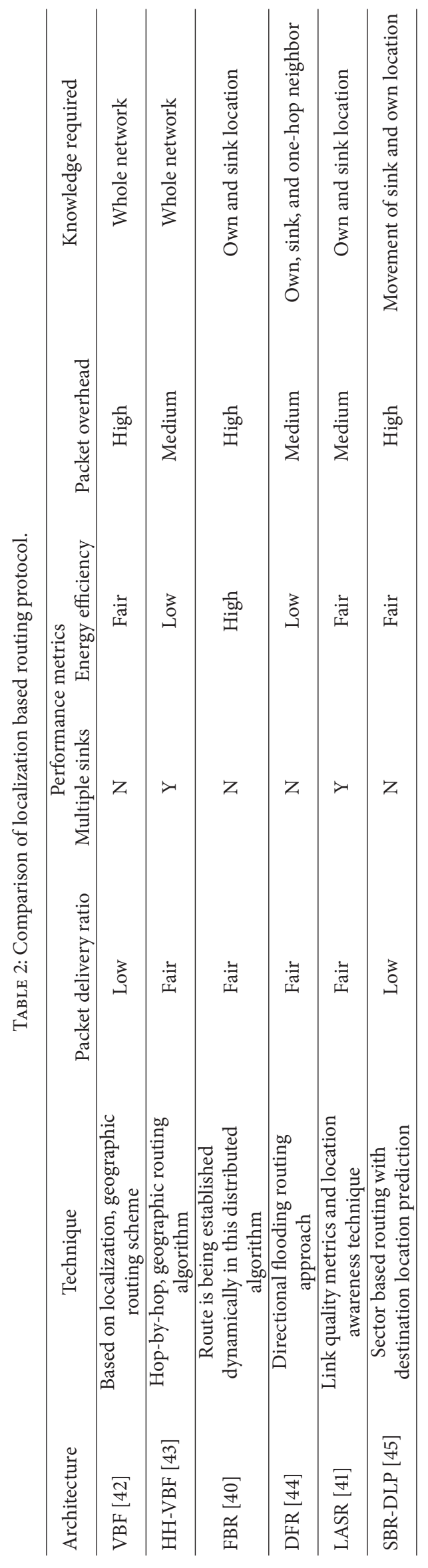




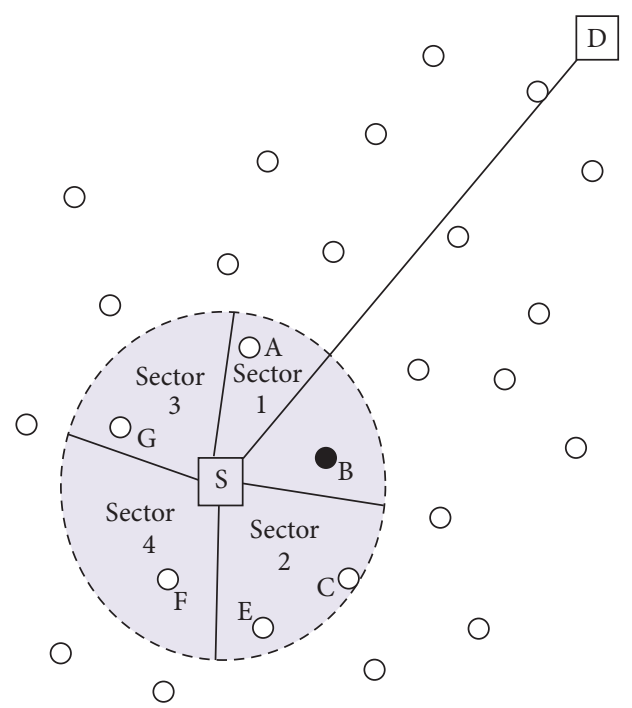

FIGURE 5: Forwarder selection at the sender (SBR-DLP).

mechanism to final destination. In this protocol it is assumed that every node must know the location of itself and onehop-away node and final destination. Only a limited number of nodes take part in routing process. In this scheme the flooding zone is decided by FS and FD, where $S$ is source node and $\mathrm{D}$ is destination node while $\mathrm{F}$ is receiving node, usually sink.

5.7. Location-Aware Source Routing. Location-Aware Source Routing [41] is an advanced version of DSR. Link quality metrics and location awareness technique are used by LASR routing scheme. Earlier protocol only depended upon shortest path metrics and in the end it led to bad performance.

\subsection{Sector Based Routing with Destination Location Predica-} tion. In UWSN many localization based routing algorithms have been introduced and it is considered that network with already known geographical location of other nodes improves energy efficiency. It helps in minimizing control messages and network overhead. SBR-DLP [45] is a localization based routing protocol. In this protocol not only other nodes but also destination nodes are considered to be mobile. In SBR-DLP sensor does not need to carry information about neighbors. In this algorithm it is considered that every node must know its own location information and preplanned movement of destination nodes. Hop-by-hop mechanism is used to forward data to destination nodes. In Figure 5 a node $S$ has a data packet that is needed to be sent to the destination D. In order to do so, next hop is found by broadcasting a Chk_Ngb packet which has its current location as well as its Node-ID. The neighbor node will receive Chk_Ngb, whether it is near to destination node $\mathrm{D}$. The nodes that meet these conditions will reply to the node $S$ by sending a Chk_Ngb_Reply packet.

\section{Localization-Free Routing Protocols}

This category includes those routing protocols which do not require any earlier geographical information of the network. These protocols perform their operation without having location information of other nodes.

In these kinds of routing protocols, a sensor node does not require any prior network information of other network nodes $[46,47]$. Most of the localization protocols work on flooding phenomenon and are considered to have fast packet delivery ratio and low end-to-end delay [10, 11].

In Depth Based Routing protocol [27], prenetwork information is not needed. It just takes the depth of sensor nodes into account and forwards a packet. It actually compares the depth of sending node with that of receiving node so if depth of sender node is higher than that of receiver node then it will forward the data; otherwise it will ignore that node.

Similarly in [39], Energy-Efficient DBR takes into account the depth information as well as residual energy of the node at the time of sending data.

This category includes those routing protocols which do not require any earlier geographical information of the network. These protocols perform their operation without having location information of other nodes. In these kinds of routing protocols, a sensor node does not require any prior network information of other network nodes [46, 47]. Most of the localization protocols work on flooding phenomenon and are considered to have fast packet delivery ratio and low end-to-end delay $[10,11]$.

In [27], Depth Based Routing does not need any prenetwork information. It just takes the depth of sensor nodes into account and forwards a packet. It actually compares the depth of sending node with that of receiving node so if the depth of sender node is higher than that of receiver node then it will forward the data; otherwise, it will ignore that node. Similarly in [39], Energy-Efficient DBR takes into account the depth information as well as residual energy of the node at the time of sending data. A detailed summary of localization-free routing protocol has been provided in Table 3 .

6.1. Depth Based Routing. Many routing protocols in UWSN need geographic location of the nodes in order to communicate. Localization itself requires much energy and calculations. Depth Based Routing (DBR) protocol [27] does not need any earlier information. DBR needs depth information of each node. When a node with the highest depth senses some movement, it starts sending data to higher nodes, such that it compares its depth with neighbor nodes. If send packets to only those nodes whose depth is lower than sender node. The same process continuous until packet is received by sink. This protocol is mainly concerned about depth of node. Sinks are provided with continuous power.

Figure 6 defines next node selection in Depth Based Routing protocol, where three nodes N1, N2, and N3 are in communication range of sender S. In first step depth of receiver nodes is checked. N1 and N2 are found eligible for data forwarding as their depth is less than sender node S.

DBR does not take into account any other parameters than depth, which leads to a few drawbacks. Life time of the 


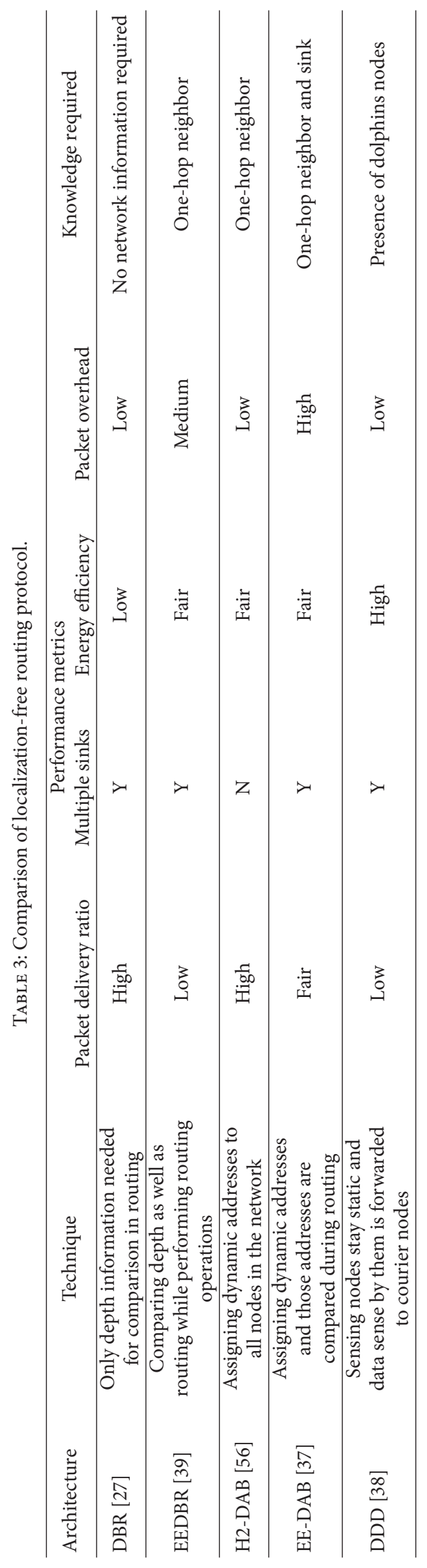




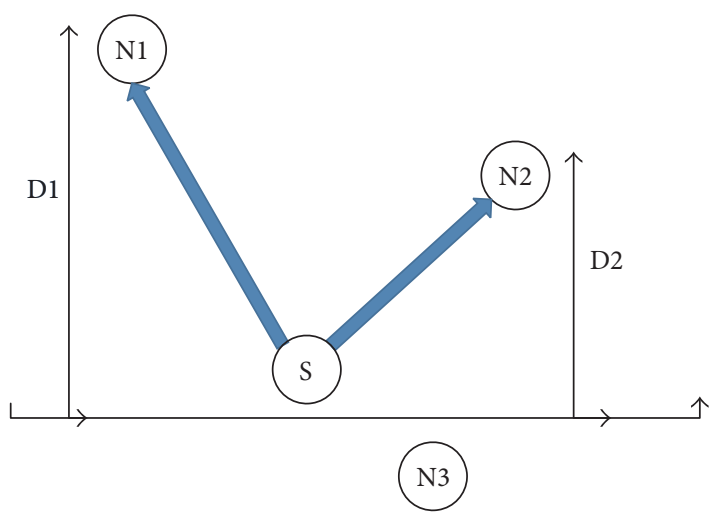

FIgURE 6: Node selection in DBR.

network where DBR is used, will be less as it will always send data to the same higher node as no check has been observed. This will lead to death of the node. Path selection in DBR has no proper mechanism, as no proper strategy is used for efficient or short path selection.

6.2. Energy-Efficient Depth Based Routing. In EnergyEfficient Depth Based Routing (EE-DBR) [39] protocol when a node forwards its data, it takes into account the depth of the receiver node and its residual energy. When a node forwards data it first compares the depth of the receiver node with itself; if the depth of receiver node is smaller than sender then it checks the residual energy of receiver node. Node with higher residual energy and less depth among the neighbors is selected as next hop for communication. Every node has information on depth and residual energy about their neighbors, so the node with most suitable parameter is selected for communication.

EE-DBR has not defined any mechanism for multipath communication. A node may forward data to node which is far away from sender and will result in higher energy consumption. Similarly no parameter has been taken into account to define a shortest and efficient path towards sink.

6.3. Hop-by-Hop-Dynamic Addressing Based. In Hop-byHop-Dynamic Addressing Based (H2-DAB) routing [56], dynamic addresses are assigned to nodes and destination ID is set to " 0 " for all nodes. No prenetwork information is required in this protocol. In first step of network setup, a HopID is assigned to each node. Every node in the network will have two types of addresses, Node-ID and HopID. NodeID is physical address of node while Node-ID changes with change in location.

HopIDs are assigned from top to bottom. Nodes having lower depth are assigned lower HopID, like node which is nearest will have HopID of 1 . Similarly nodes having higher depth are assigned higher HopIDs. H2-DAB supports multisink architecture, where multiple sinks are installed on shore. Those sinks are connected with each other through radio communication. Data packet received at any sink is considered received.
However, this approach might create problems where a node cannot find in range any node which has lower HopID from sender node. In case of failure at finding suitable node in first attempt, sender will retransmit data packet and then wait again for specified amount of time. If results were still the same then sender node will forward data to a node having nearly or equal HopID as sender node. This process results in energy wastage.

6.4. Energy-Efficient Dynamic Addressing Based Routing. In Energy-Efficient Dynamic Address Based (EE-DAB) routing [37], in this type of dynamic addressing scheme, every node is assigned Node-ID, S-HopID, and C-HopID. Node-ID shows the physical address of node; S-HopID consists of two digits which show how many hops away one or two sinks are. Left hop is considered as the highest priority and is selected as primary route. The C-HopID also consists of 2 digits which show how many hops the receiving nodes are away from courier nodes. Figure 7 describes how to make the selection of nodes for sending data packets. As source node N23 is having a data packet, with their own HopIDs 66 and 99 (CHopIDs for all the nodes are 99 because of nonavailability of courier node in the area), a simple query message will be sent asking neighbor nodes about their HopID. In its reply an inquiry reply packet is sent back to sender node which contains only three fields, that is, Node-ID, S-HopID, and CHopID of replying nodes, where nodes N15, N16, N22, N24, and N25 lie in communication range and will reply with their Node-ID and HopID. After receiving, N23 sorts out these inquiry replies and gets the minimum HopID. As diagram shows, nodes N15 and N16 are declared as the candidates for the next hop, because both of them have smaller HopID as compared to HopID of the source node but N15 qualifies for this competition because of its backup link which is also smaller than N16. The source node will forward the data packet with N15 Node-ID as a next hop. In other cases, if two nodes respond with the same minimum HopID then the node that replied earlier will be selected as next hop for further communication.

6.5. Mobile Delay-Tolerant Routing. As acoustic communication uses more energy than that of radio communication, wireless sensor nodes are battery-operated, and higher energy consumption leads to a serious problem, thus energy efficiency has become a major problem in underwater wireless sensor networks. In [38], a delay-tolerant protocol is proposed which is called delay-tolerant data dolphin scheme. This proposed scheme is designed for delay-tolerant systems and applications. In these protocols all the sensing nodes stay static and data sensed by static nodes are passed on to data dolphin which acts as courier nodes. So in this methodology high energy consumed hop-by-hop communication is avoided. Data dolphins which act as courier nodes are provided with continuous energy. In the architecture all the static nodes are deployed in the sea bed. These static sensors go into sleep mode if there is no data to sense and they periodically wake up when they sense some data. After sensing some kind of desired data they simply forward this data to courier nodes which are also called data dolphins. 




Figure 7: Hop selection EE-DAB.

These data dolphins take this data and deliver it to base station or sink. The number of dolphin nodes depends on the kind of network and its application and the number of nodes deployed in the network.

\section{Conclusion}

In this survey, state of the art routing protocols in UWSN have been presented. Almost all routing protocols in UWSN are presented in tabular form. UWSN environment is very different as compared to terrestrial wireless sensors network. Acoustic channels consume a large amount of energy with very less amount of data transferred. Furthermore, the flow of water makes it quite difficult for sensor nodes to forward data in a stable scenario. Routing in UWSN is considered to be a very important part in respect of energy efficiency. Among all defined protocols above, one cannot be selected the best because every protocol has some cons and pros. As a newly emerging technology, a lot of work has to be done with respect to energy efficiency, end-to-end delay, propagation delay, and path loss. Energy-efficient routing schemes play a vital role in extending life time of network and efficient path selection for data forwarding. Keeping in view the limitations in UWSN, energy-efficient schemes are encouraged. Underwater sensors are used in multiple application scenarios and separate mechanism is adopted when proposing a new routing scheme. In recent years, routing in UWSN has attracted a large number of researchers in this area. Still this area carries certain challenges like topology management, energy efficiency, data retransmission, and path loss, which needs researcher's attention.

\section{Conflicts of Interest}

The authors declare that there are no conflicts of interest.

\section{References}

[1] E. Felemban, F. K. Shaikh, U. M. Qureshi, A. A. Sheikh, and S. B. Qaisar, "Underwater sensor network applications: a comprehensive survey," International Journal of Distributed Sensor Networks, vol. 2015, Article ID 896832, 2015.

[2] K. Ali and H. Hassanein, "Underwater wireless hybrid sensor networks," in Proceedings of 13th IEEE Symposium on Computers and Communications, ISCC 2008, pp. 1166-1171, July 2008.

[3] I. F. Akyildiz, D. Pompili, and T. Melodia, "Challenges for efficient communication in underwater acoustic sensor networks," ACM Sigbed Review, vol. 1, no. 2, pp. 3-8, 2004.

[4] I. F. Akyildiz, D. Pompili, and T. Melodia, "Underwater acoustic sensor networks: research challenges," Ad Hoc Networks, vol. 3, no. 3, pp. 257-279, 2005.

[5] D. Kim, D. Shin, and H. Yoo, "Providing service-connectivity in delay tolerant networks," in Proceedings of ALPIT 2008, 7th International Conference on Advanced Language Processing and Web Information Technology, pp. 471-476, July 2008.

[6] J. Heidemann, W. Ye, J. Wills, A. Syed, and Y. Li, "Research challenges and applications for underwater sensor networking," in Wireless Communications and Networking Conference, vol. 1, pp. 228-235, WCNC, 2006.

[7] H. Yu, N. Yao, and J. Liu, "An adaptive routing protocol in underwater sparse acoustic sensor networks," Ad Hoc Networks, vol. 34, pp. 121-143, 2015.

[8] S. Climent, A. Sanchez, J. V. Capella, N. Meratnia, and J. J. Serrano, "Underwater acoustic wireless sensor networks: advances and future trends in physical, mac and routing layers," Sensors, vol. 14, no. 1, pp. 795-833, 2014. 
[9] M. Maalej, S. Cherif, and H. Besbes, "QoS and energy aware cooperative routing protocol for wildfire monitoring wireless sensor networks," The Scientific World Journal, vol. 2013, Article ID 437926, 11 pages, 2013.

[10] M. Erol and S. Oktug, "A localization and routing framework for mobile underwater sensor networks," in Proceedings of 2008 IEEE INFOCOM Workshops, April 2008.

[11] C. Giantsis and A. A. Economides, "Comparison of routing protocols for underwater sensor networks: a survey," International Journal of Communication Networks and Distributed Systems, vol. 7, no. 3-4, pp. 192-228, 2011.

[12] W. R. Heinzelman, A. Chandrakasan, and H. Balakrishnan, "Energy-efficient communication protocol for wireless microsensor networks," in Proceedings of the 33rd annual Hawaii international conference on, 10 pages, IEEE, 2000.

[13] Z. Guo, G. Colombi, B. Wang, J.-H. Cui, D. Maggiorinit, and G. P. Rossi, "Adaptive routing in underwater delay/disruption tolerant sensor networks," in Proceedings of the 5th Annual Conference on Wireless on Demand Network Systems and Services (WONS '08), pp. 31-39, January 2008.

[14] R. Manjula and S. S. Manvi, "Issues in underwater acoustic sensor networks," in Proceedings of, vol. 3, p. 101, 2011.

[15] M. Ayaz, I. Baig, A. Abdullah, and I. Faye, "A survey on routing techniques in underwater wireless sensor networks," Journal of Network and Computer Applications, vol. 34, no. 6, pp. 19081927, 2011.

[16] M. Patil and R. C. Biradar, "A survey on routing protocols in Wireless Sensor Networks," in Proceedings of the 18th IEEE International Conference on Networks (ICON '12), pp. 86-91, December 2012.

[17] S. Lindsey and C. S. Raghavendra, "PEGASIS: power-efficient gathering in sensor information systems," in Proceedings of the IEEE Aerospace Conference, vol. 3, pp. 1125-1130, March 2002.

[18] A. Manjeshwar and D. P. Agrawal, "TEEN: a routing protocol for enhanced efficiency in wireless sensor networks," in Proceedings of Proceedings 15th International Parallel and Distributed Processing Symposium (IPDPS '01), vol. 1, pp. 2009-2015, 2001.

[19] Z. Zhou, Z. Peng, J.-H. Cui, and Z. Shi, "Efficient multipath communication for time-critical applications in underwater acoustic sensor networks," IEEE/ACM Transactions on Networking, vol. 19, no. 1, pp. 28-41, 2011.

[20] Z. Zhou, Z. Peng, J.-H. Cui, Z. Shi, and A. Bagtzoglou, "Scalable localization with mobility prediction for underwater sensor networks," IEEE Transactions on Mobile Computing, vol. 10, no. 3, pp. 335-348, 2011.

[21] M. Zorzi, P. Casari, N. Baldo, and A. F. Harris III, "Energyefficient routing schemes for underwater acoustic networks," IEEE Journal on Selected Areas in Communications, vol. 26, no. 9, pp. 1754-1766, 2008.

[22] J.-H. Cui, J. Kong, M. Gerla, and S. Zhou, "The challenges of building scalable mobile underwater wireless sensor networks for aquatic applications," IEEE Network, vol. 20, no. 3, pp. 12-18, 2006.

[23] V. Chandrasekhar, W. K. G. Seah, Y. S. Choo, and H. V. Ee, "Localization in underwater sensor networks - Survey and challenges," in Proceedings of the 1st ACM International Workshop on Underwater Networks (WUWNet '06), pp. 33-40, Los Angeles, Calif, USA, September 2006.

[24] P. Xie, Z. Zhou, Z. Peng, J.-H. Cui, and Z. Shi, "Void avoidance in Three-dimensional mobile underwater sensor networks," Lecture Notes in Computer Science (including subseries Lecture Notes in Artificial Intelligence and Lecture Notes in Bioinformatics), vol. 5682, pp. 305-314, 2009.

[25] M. G. Zapata and N. Asokan, "Securing ad hoc routing protocols," in Proceedings of the 1st ACM workshop on Wireless security, p. 10, 2002.

[26] M. Goetz and I. Nissen, "Guwmanetmulticast routing in underwater acoustic networks," in Communications and Information Systems Conference, p. 1, MCC, 2012.

[27] H. Yan, Z. J. Shi, and J.-H. Cui, "DBR: Depth-based routing for underwater sensor networks," Lecture Notes in Computer Science (including subseries Lecture Notes in Artificial Intelligence and Lecture Notes in Bioinformatics), vol. 4982, pp. 72-86, 2008.

[28] W. Wang, J. Kong, B. Bhargava, and M. Gerla, "Visualisation of wormholes in underwater sensor networks: a distributed approach," in Proceedings of, vol. 3, pp. 10-23, 2008.

[29] M. Domingo, "Securing underwater wireless communication networks," IEEE Wireless Communications, vol. 18, no. 1, pp. 2228, 2011.

[30] K. Chen, M. Ma, E. Cheng, F. Yuan, and W. Su, "A survey on mac protocols for underwater wireless sensor networks," IEEE Communications Surveys Tutorials, vol. 16, no. 3, pp. 1433-1447, 2014.

[31] L.-C. Kuo and T. Melodia, "Tier-based underwater acoustic routing for applications with reliability and delay constraints," in Proceeding of IEEE Intl. Workshop on Wireless Mesh and Ad Hoc Networks, pp. 1-6, WiMAN.

[32] G. Han, J. Jiang, N. Sun, and L. Shu, "Secure communication for underwater acoustic sensor networks," IEEE Communications Magazine, vol. 53, no. 8, pp. 54-60, 2015.

[33] K. R. Anupama, A. Sasidharan, and S. Vadlamani, "A locationbased clustering algorithm for data gathering in $3 \mathrm{D}$ underwater wireless sensor networks," in Proceedings of 2008 International Symposium on Telecommunications, IST 2008, pp. 343-348, August 2008.

[34] J. L. Tangorra, S. N. Davidson, I. W. Hunter et al., "The development of a biologically inspired propulsor for unmanned underwater vehicles," IEEE Journal of Oceanic Engineering, vol. 32, no. 3, pp. 533-550, 2007.

[35] W. K. G. Seah and H. P. Tan, "Multipath virtual sink architecture for wireless sensor networks in harsh environments," in Proceedings of 1st International Conference on Integrated Internet Ad hoc and Sensor Networks, fra, May 2006.

[36] N. Ilyas, M. Akbar, R. Ullah et al., "SEDG: Scalable and efficient data gathering routing protocol for underwater WSNs," in Proceedings of The International Conference on Ambient Systems, Networks and Technologies, ANT-2015, the International Conference on Sustainable Energy Information Technology, SEIT-2015, pp. 584-591, gbr, June 2015.

[37] M. Ayaz, A. Abdullah, I. Faye, and Y. Batira, "An efficient dynamic addressing based routing protocol for underwater wireless sensor networks," Computer Communications, vol. 35, no. 4, pp. 475-486, 2012.

[38] E. Magistretti, J. Kong, U. Lee, M. Geria, P. Bellavista, and A. Corradi, "A mobile delay-tolerant approach to long-term energy-efficient underwater sensor networking," in Proceedings of the IEEE Wireless Communications and Networking Conference (WCNC '07), pp. 2868-2871, IEEE, March 2007.

[39] A. Wahid and D. Kim, "An energy efficient localization-free routing protocol for underwater wireless sensor networks," International Journal of Distributed Sensor Networks, vol. 2012, Article ID 307246, 11 pages, 2012. 
[40] J. M. Jornet, M. Stojanovic, and M. Zorzi, "Focused beam routing protocol for underwater acoustic networks," in in Proceedings of the third ACM international workshop on Underwater Networks, pp. 75-82, 2008.

[41] E. A. Carlson, P.-P. Beaujean, and E. An, "Location-aware routing protocol for underwater acoustic networks," in Proceedings of OCEANS 2006, September 2006.

[42] P. Xie, J. H. Cui, and L. Lao, "VBF: vector-based forwarding protocol for underwater sensor networks, networking technologies, services, and protocols," in Networking Technologies, Services, and Protocols; Performance of Computer and Communication Networks; Mobile and Wireless Communications Systems, vol. 3976 of Lecture Notes in Computer Science, pp. 1216-1221, Springer, Berlin, Germany, 2006.

[43] N. Nicolaou, A. See, P. Xie, J.-H. Cui, and D. Maggiorini, "Improving the robustness of location-based routing for underwater sensor networks," in OCEANS 2007-Europe, p. 1, IEEE, 2007.

[44] D. Hwang and D. Kim, "DFR: directional flooding-based routing protocol for underwater sensor networks," in Proceedings of the IEEE OCEANS, pp. 1-7, IEEE, Quebec, Canada, September 2008.

[45] N. Chirdchoo, W.-S. Soh, and K. C. Chua, "Sector-based routing with destination location prediction for underwater mobile networks," in Proceedings of the International Conference on Advanced Information Networking and Applications Workshops (WAINA '09), pp. 1148-1153, IEEE, Bradford, UK, May 2009.

[46] N. Aitsaadi, N. Achir, K. Boussetta, and G. Pujolle, "Differentiated underwater sensor network deployment," in Oceans, p. 1, IEEE, 2007.

[47] M. Ayaz and A. Abdullah, "Underwater wireless sensor networks: Routing issues and future challenges," in Proceedings of 7th International Conference on Advances in Mobile Computing and Multimedia, MoMM2009, pp. 370-375, mys, December 2009.

[48] D. Pompili, T. Melodia, I. F. Akyildiz et al., "A resilient routing algorithm for long-term applications in underwater sensor networks," of Mediterranean Ad Hoc Networking Workshop (Med-Hoc-Net), 2006.

[49] L. Wei, Y. Haibin, L. Lin, L. Bangxiang, and C. Chang, "Information-carrying based routing protocol for underwater acoustic sensor network," in Proceedings of 2007 IEEE International Conference on Mechatronics and Automation, ICMA 2007, pp. 729-734, August 2007.

[50] M. C. Domingo and R. Prior, "A distributed clustering scheme for underwater wireless sensor networks," in Proceedings of the 18th Annual IEEE International Symposium on Personal, Indoor and Mobile Radio Communications (PIMRC '07), pp. 1-5, Athens, Ga, USA, September 2007.

[51] P. Sun, W. K. G. Seah, and P. W. Q. Lee, "Efficient data delivery with packet cloning for underwater sensor networks," in Proceedings of International Symposium on Underwater Technology, UT 2007 - International Workshop on Scientific Use of Submarine Cables and Related Technologies 2007, pp. 34-41, April 2007.

[52] P. Wang, C. Li, and J. Zheng, "Distributed minimum-cost clustering protocol for UnderWater Sensor Networks (UWSNs)," in Proceedings of 2007 IEEE International Conference on Communications, ICC'07, pp. 3510-3515, June 2007.

[53] J. Chen, X. Wu, and G. Chen, "REBAR: A reliable and energy balanced routing algorithm for UWSNs," in Proceedings of 7th International Conference on Grid and Cooperative Computing, GCC 2008, pp. 349-355, October 2008.
[54] C.-H. Yang and K.-F. Ssu, "An energy-efficient routing protocol in underwater sensor networks," in Proceedings of 3rd International Conference on Sensing Technology, ICST 2008, pp. 114-118, December 2008.

[55] T. Li, "Multi-sink opportunistic routing protocol for underwater mesh network," in Proceedings of the International Conference on Communications, Circuits and Systems (ICCCAS '08), pp. 405409, May 2008.

[56] M. Ayaz and A. Abdullah, "Hop-by-hop dynamic addressing based (H2-DAB) routing protocol for underwater wireless sensor networks," in Proceedings of the International Conference on Information and Multimedia Technology (ICIMT '09), pp. 436-441, December 2009.

[57] M. Ayaz, A. Abdullah, and L. T. Jung, "Temporary cluster based routing for underwater wireless sensor networks," in Proceedings of 2010 International Symposium on Information Technology, ITSim'10, pp. 1009-1014, June 2010.

[58] S. Gopi, K. Govindan, D. Chander, U. B. Desai, and S. N. Merchant, "E-PULRP: energy optimized path unaware layered routing protocol for underwater sensor networks," IEEE Transactions on Wireless Communications, vol. 9, no. 11, pp. 3391-3401, 2010.

[59] T. Hu and Y. Fei, "QELAR: a machine-learning-based adaptive routing protocol for energyefficient and lifetime-extende $\mathrm{d}$ underwater sensor networks," IEEE Transactions on Mobile Computing, vol. 9, no. 6, pp. 796-809, 2010.

[60] S. K. Dhurandher, M. S. Obaidat, and M. Gupta, "A novel geocast technique with hole detection in underwater sensor networks," in Proceedings of 2010 ACS/IEEE International Conference on Computer Systems and Applications, AICCSA 2010, tun, May 2010.

[61] S. Zhang, D. Li, and J. Chen, "A link-state based adaptive feedback routing for underwater acoustic sensor networks," IEEE Sensors Journal, vol. 13, no. 11, pp. 4402-4412, 2013.

[62] Y.-S. Chen and Y.-W. Lin, "Mobicast routing protocol for underwater sensor networks," IEEE Sensors Journal, vol. 13, no. 2, pp. 737-749, 2013.

[63] Y. Noh, U. Lee, P. Wang, B. S. C. Choi, and M. Gerla, "VAPR: void-aware pressure routing for underwater sensor networks," IEEE Transactions on Mobile Computing, vol. 12, no. 5, pp. 895908, 2013.

[64] M. R. Jafri, M. M. Sandhu, K. Latif, Z. A. Khan, A. U. H. Yasar, and N. Javaid, "Towards delay-sensitive routing in underwater wireless sensor networks," in Proceedings of 5th International Conference on Emerging Ubiquitous Systems and Pervasive Networks, EUSPN 2014 and the 4th International Conference on Current and Future Trends of Information and Communication Technologies in Healthcare, ICTH 2014, pp. 228-235, can, September 2014.

[65] Z. Li, N. Yao, and Q. Gao, "Relative distance based forwarding protocol for underwater wireless networks," in Proceedings of, 2014.

[66] T. Ali, L. T. Jung, and I. Faye, "Diagonal and vertical routing protocol for underwater wireless sensor network," ProcediaSocial and Behavioral Sciences, vol. 129, pp. 372-379, 2014.

[67] S. Basagni, C. Petrioli, R. Petroccia, and D. Spaccini, "CARP: a channel-aware routing protocol for underwater acoustic wireless networks," Ad Hoc Networks, vol. 34, pp. 92-104, 2015.

[68] M. Gao, Z. Chen, X. Yao, and N. Xu, "Harmonic potential field based routing protocol for $3 \mathrm{~d}$ underwater sensor networks," in in Proceedings of the 11th ACM International Conference on Underwater Networks \& Amp; Systems, p. 38, 2016. 
[69] Y. Noh, U. Lee, S. Lee et al., "HydroCast: pressure routing for underwater sensor networks," IEEE Transactions on Vehicular Technology, vol. 65, no. 1, pp. 333-347, 2016.

[70] E. Isufi, H. Dol, and G. Leus, "Advanced flooding-based routing protocols for underwater sensor networks," Eurasip Journal on Advances in Signal Processing, vol. 2016, no. 1, article no. 52, 2016.

[71] G. Han, L. Liu, N. Bao, J. Jiang, W. Zhang, and J. J. Rodrigues, "Arep: an asymmetric link-based reverse routing protocol for underwater acoustic sensor networks," Journal of Network and Computer Applications, 2017.

[72] S. Rani, S. H. Ahmed, J. Malhotra, and R. Talwar, "Energy efficient chain based routing protocol for underwater wireless sensor networks," Journal of Network and Computer Applications, 2017. 


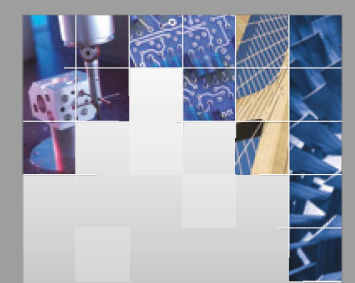

\section{Enfincering}
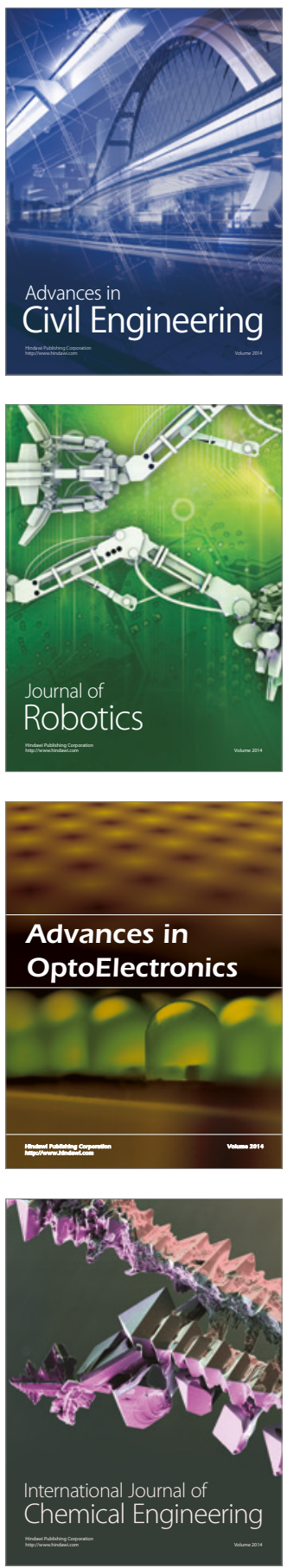

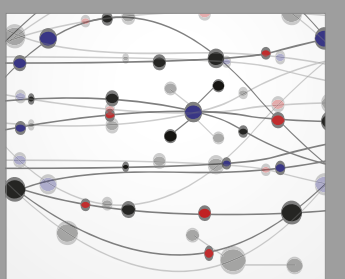

The Scientific World Journal

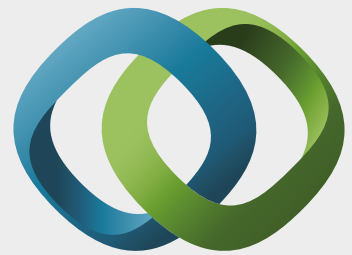

\section{Hindawi}

Submit your manuscripts at

https://www.hindawi.com
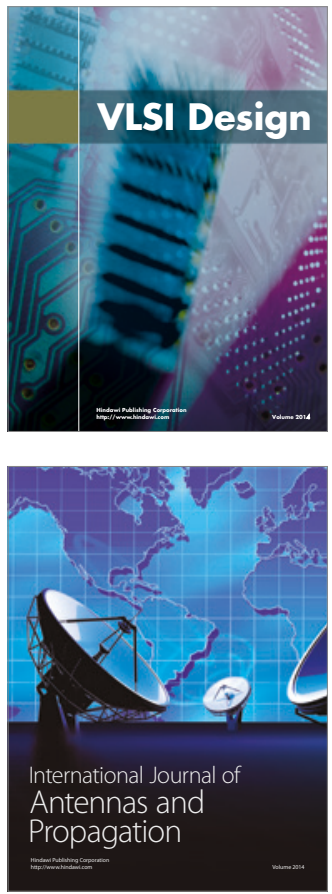

\section{Rotating}

Machinery
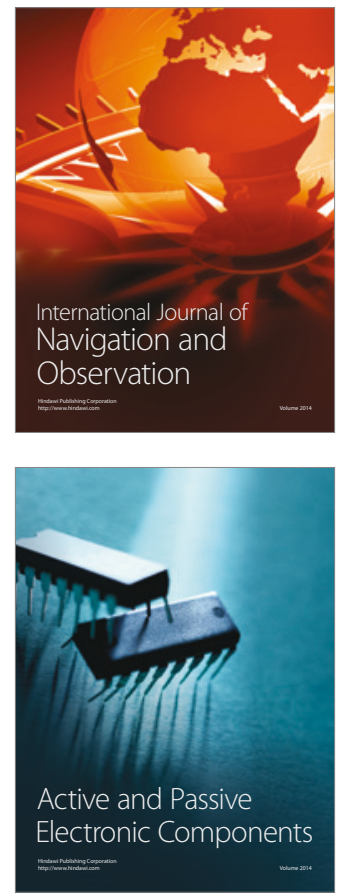
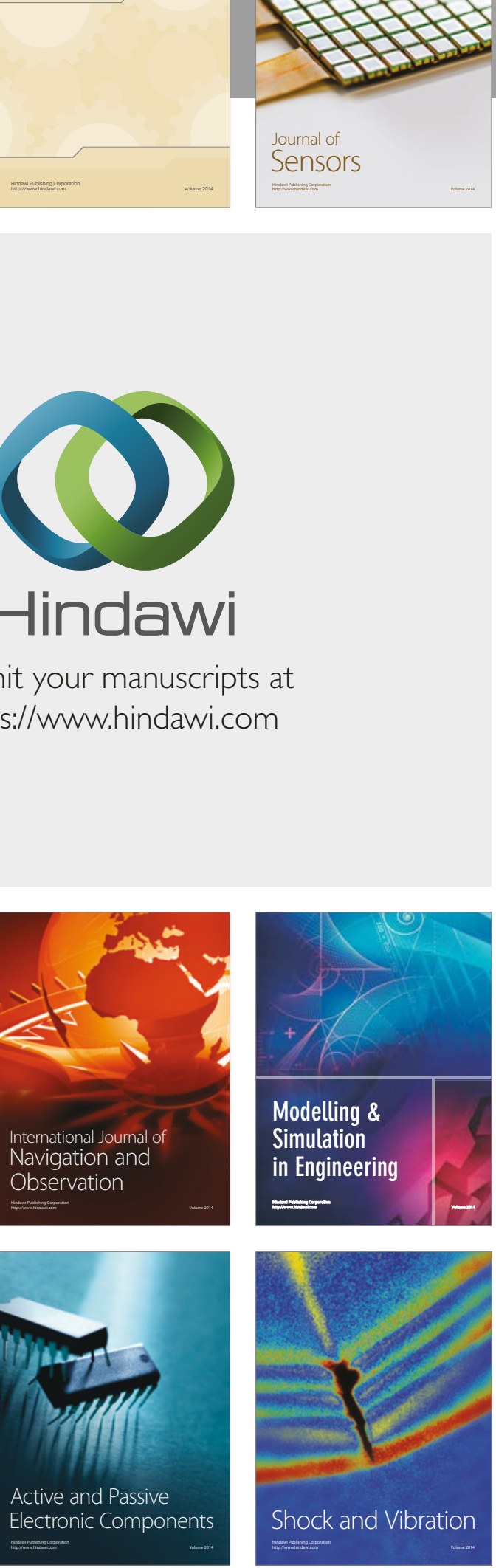
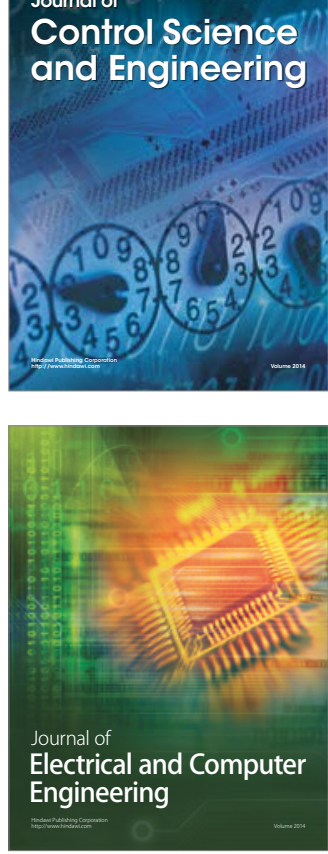

Distributed

Journal of

Control Science

and Engineering
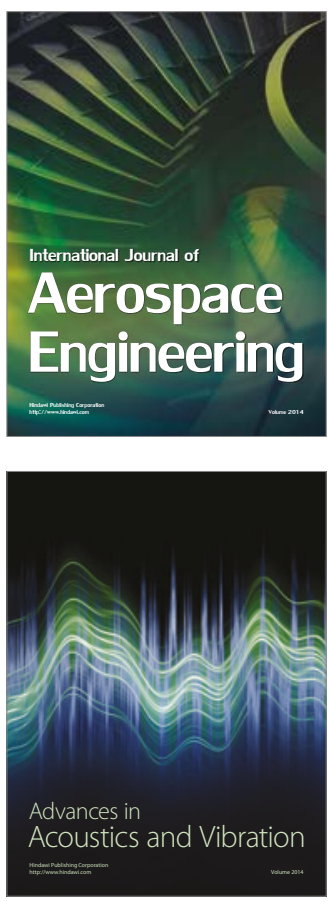

Sensor Networks 